\title{
Grain Refinement and Texture Change in Interstitial Free Steels after Severe Rolling and Ultra-short Annealing
}

\author{
Ana Carmen da Costa REIS, Lieven BRACKE, Roumen PETROV, Wlodzimierz Jacek KALUBA ${ }^{11}$ \\ and Leo KESTENS
}

Ghent University, Department of Metallurgy and Materials Science, Technologiepark 903 B-9052, Ghent, Belgium. 1) Université du Littoral, Laboratoire Thermo Physique Matière Condensée, Côte d’Opale, 62968 Longuenesse, France.

(Received on November 25, 2002; accepted in final form on February 1, 2003)

\begin{abstract}
A Ti-stabilized interstitial free steel was highly cold deformed to a reduction of $95 \%$ and subsequently submitted to extremely short annealing cycles with heating rates varying between $300^{\circ} \mathrm{C} / \mathrm{s}$ and $4500^{\circ} \mathrm{C} / \mathrm{s}$ followed by water quench at various temperatures. The microstructural and textural development was studied through various consecutive stages: partially recrystallized, fully recrystallized and after $\alpha \rightarrow \gamma \rightarrow \alpha$ transformation. It was found that irrespective of the heating rate the recrystallization has completely terminated before the onset of the ferrite to austenite phase transformation. In the fully recrystallized condition, ultrarapid heating gave rise to substantially refined structures with an average ferrite grain size of $6 \mu \mathrm{m}$. It was also observed that this grain refinement saturates with heating rates beyond $1000^{\circ} \mathrm{C} / \mathrm{s}$.

The transformation structures obtained by ultra fast heating to temperatures in the full austenite region exhibited remarkably coarser grains than the ones observed after ferrite annealing. This coarsening effect was attributed to the effects of heterogeneous nucleation during phase transformation as $\mathrm{C}$ was initially present as $\mathrm{TiC}$ precipitates in the ferrite matrix.

With regard to the texture formation, the characteristic $\{111\}$ deep drawing fibre of cold rolled IF steels was observed, irrespective of the heating rate, in an annealing treatment as short as $0.3 \mathrm{~s}$. After the forward and reverse $\alpha \rightarrow \gamma$ transformation, the ensuing ferrite texture displayed a strong memory effect, as the $\{111\}$ fibre was even more intense after the double transformation than before.
\end{abstract}

KEY WORDS: ultra-short annealing; recrystallization; grain size; textures; $\alpha \rightarrow \gamma \rightarrow \alpha$ transformation.

\section{Introduction}

Recently, a lot of effort has been spent to obtain ultrafine grain structures with an average grain size in the submicron or even in the nanometer range. Up to now, the majority of the work was done on conventional FCC metals such as $\mathrm{Al}, \mathrm{Cu}$, and $\mathrm{Ni}^{1-3)}$ and far less research was carried out on BCC alloys such as Fe-based structures. The techniques developed hitherto can be divided in two different categories: bottom-up and top-down procedures. The bottom-up procedures include all tentatives to produce bulk material from nanostructured components, such as metal powders. Ball milling or mechanical alloying procedures are often used to structurally refine powders to the order of tens or even units of nanometers. In a subsequent stage these powders are compacted into a product or a sample of macroscopic dimensions. Hot compression or hot isostatic pressing are widely used techniques, but recently also a hot rolling technology was applied ${ }^{4)}$.

With the top-down procedures, in contrast to the bottomup procedures, it is intended to establish an ultra fine structure in a bulk material with macroscopic dimensions. These procedures include various techniques such as high pressure torsion (HPT), equal channel angular processing (ECAP) or accumulated roll bonding (ARB), which could be qualified as severe plastic deformation techniques (SPD). From the various SPD techniques ECAP is perhaps the most intensely studied. Nanoscale structures have been developed by ECAP for $\mathrm{Cu}, \mathrm{Al}$ and Ti-alloys which displayed grain sizes in the range of 100, 200 and $500 \mathrm{~nm}$, respectively $^{2}$. Only recently a study was published on a nanostructured Fe-based alloy with average grain size of $300 \mathrm{~nm}^{5,6)}$.

HPT offers the potential to obtain extremely high strains $(\varepsilon \sim 600)^{7,8)}$ without any risk of fracturing the material. Furthermore, it was shown that an isostatic pressure of the order of $5 \mathrm{GPa}$ largely contributes to a step increase of the dislocation density with increasing strain. ${ }^{1)}$ With an accumulated strain of 50, Zehetbauer reports a grain size of 450 $\mathrm{nm}$ in a $\mathrm{Cu}$ alloy ${ }^{8)}$ with misorientations between neighboring grains exceeding $5^{\circ}$.

All of these SPD techniques, exhibit problems of different origins, which prevent them to be implemented in commercial scale production lines. Therefore, also alternative state-of-the-art manufacturing routes have been developed which are more readily applicable in current processing lines. One such an example has been called Strain Induced Dynamic Transformation (SIDT) also known as Deformation Induced Ferrite Transformation (DIFT). ${ }^{9,10)}$ In this approach the steel is rolled in the undercooled austenite 
phase. As the result of this, the metastable austenite phase transforms into ferrite. Because this transformation is strain induced it produces a very fine product structure with a grain size of the order of 1 to $4 \mu \mathrm{m}$ depending on the composition of the steel.

The present authors have also explored the possibilities of a SPD treatment by conventional rolling of sheet material. It was already shown, ${ }^{11)}$ that rolling reductions of $95 \%$ on a Ti-stabilized ultra low carbon steel do not produce sufficient grain fragmentation with a large density of high angle grain boundaries. On the basis of this work, it was concluded that an additional operation was required in order to obtain the random misorientation distribution function of a high-angle misorientation structure. Therefore, in the present work, the effect will be studied of an ultra short annealing treatment on the heavily cold rolled structure.

This study will be applied on a titanium alloyed interstitial free steel (TiIF). These steels are conventionally strengthened by $\mathrm{Mn}$ or $\mathrm{Si}$-addition, which produces the well-known high-strength deep-drawable steels. Ultra grain refinement might offer, however, an interesting ecological and economic alternative for solid solution strengthening, particularly when this can be obtained via a thermo-mechanical process, which can be applied on any state-of-theart processing line. In ultra low carbon steel, the ferrite to austenite transformation temperature is generally 150 to $200^{\circ} \mathrm{C}$ higher than the conventional recrystallization temperature. Kinetically, however, recrystallization can be a slower process than phase transformation. Therefore, by applying extremely high heating rates on the cold rolled material, it was intended to induce the $\alpha-\gamma$ transformation before the end of static recrystallization. This would operate as an instrumental grain refinement technique because it would produce a nucleation of the high temperature phase in the deformed ferrite and would automatically lead to a finer austenite structure, very much similar to the DIFT approach mentioned above. Furthermore, it is expected that the reverse transformation from high temperature austenite to room temperature ferrite will give rise to an additional refinement.

\section{Experimental}

The ultra fast annealing experiment is carried out in an industrially manufactured Ti-alloyed interstitial free steel with $0.0024 \mathrm{wt} \% \quad \mathrm{C}$ and $0.044 \mathrm{wt} \%$ Ti. After industrial rough rolling the material was finish rolled on a laboratory rolling mill with the following thermal processing parameters: a heating temperature of $1250^{\circ} \mathrm{C}$, a finishing rolling temperature of $930^{\circ} \mathrm{C}\left(>\mathrm{Ac}_{3}\right)$ and a simulated coiling temperature of $730^{\circ} \mathrm{C}$. After hot rolling the samples were cold rolled with a reduction of $95 \%(\varepsilon=3)$. The reduction schedule of hot and cold rolling were designed such that a final thickness of $1 \mathrm{~mm}$ was obtained for all the cold rolled samples.

Specimens of size $80(\mathrm{RD}) \times 20(\mathrm{TD}) \times 1(\mathrm{ND}) \mathrm{mm}$ were cut from the cold rolled sheet and a heat treatment was applied by passing a high intensity electrical current through the strip specimen. This facility allows to apply a controlled thermal cycle with heating rates as high as $7000^{\circ} \mathrm{C} / \mathrm{s}$, immediately followed by water quench or, if required, an isothermal soaking stage of approximately $100 \mathrm{~ms}$ before quenching. The temperature control was performed using an infrared pyrometer, IMPAC IW5, with operating range between 400 and $1200^{\circ} \mathrm{C}$ and a response time of $1 \mathrm{~ms}$. The specimens were annealed according to the cycles presented on Fig. 1 with initial heating rates varying from 300 to $4500^{\circ} \mathrm{C} / \mathrm{s}$ followed by water quenching after a soaking time of $50 \mathrm{~ms}$.

The metallurgical processes were studied by monitoring the microstructural evolution during recovery, recrystallization and phase transformation. Metallurgical samples, sectioned in a plane perpendicular to TD, were evaluated by Light Optical Microscopy (LOM), Scanning Electron Microscopy (SEM) and micro texture analysis. The latter was carried out using an Orientation Imaging Microscopy (OIM) attachment installed on a Philips XL30 ESEM microscope with a $\mathrm{LaB}_{6}$ filament. The specimens for optical metallography and SEM were prepared by mechanical grinding and polishing up to a $1 \mu \mathrm{m}$ diamond paste followed by etching with $2 \%$ nital. The samples for OIM
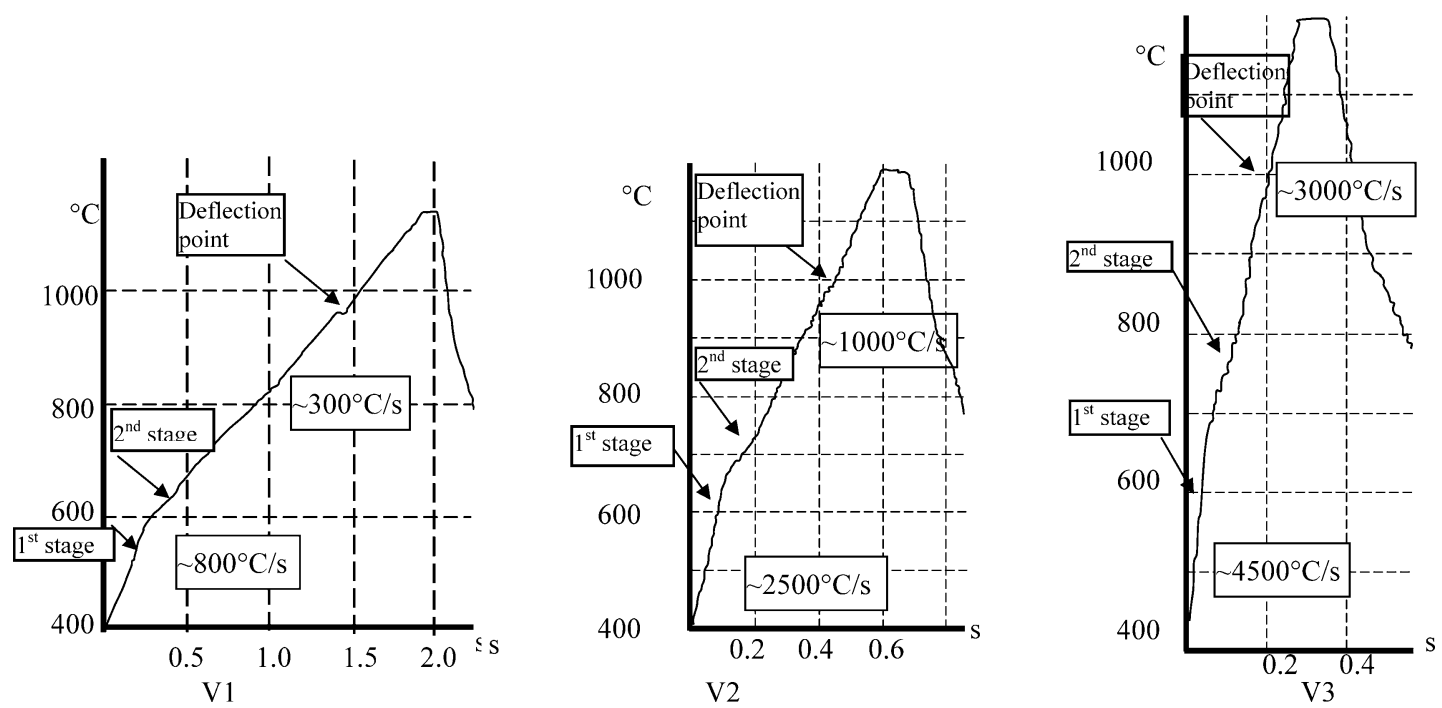

Fig. 1. Annealing cycles applied on a cold rolled IF steel with a reduction of $95 \%$. Each curve features the initial heating rate of the first stage and a reduced heating rate in a subsequent stage. The deflection point presumably marks the $\alpha-\gamma$ transformation. 


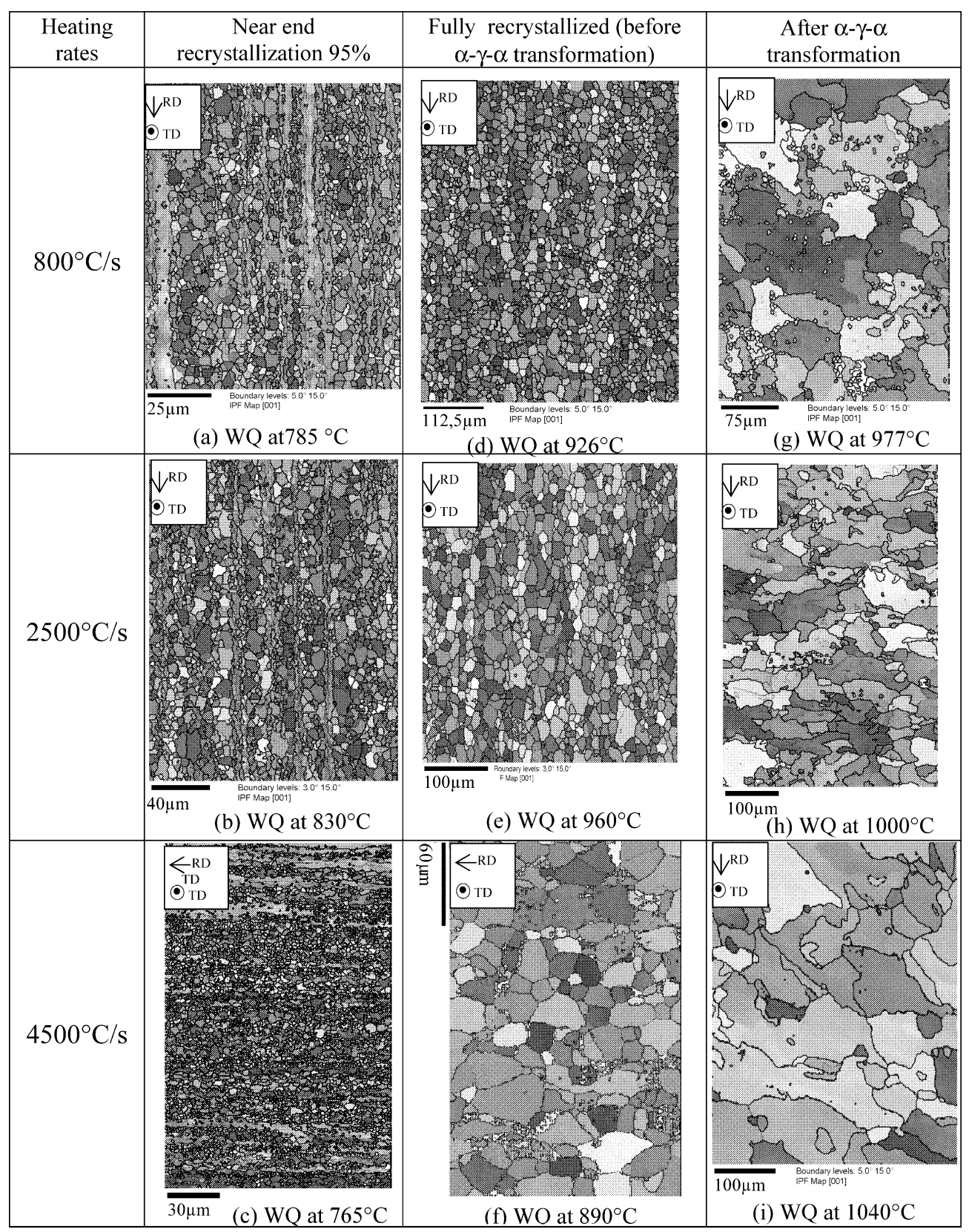

Fig. 2. Observed microstructures in TiIF steel samples submitted to ultra short annealing treatments with different heating rates. The water quench (WQ) temperature is mentioned for each micrsotructure separately.

scans were electrolytically polished and etched with $2 \%$ nital. The Kikuchi patterns were acquired and analyzed by means of the $\mathrm{TSL}^{\circledR}$ software and some of the OIM data were furthermore post-processed with the texture software developed by Van Houte. ${ }^{12)}$

\section{Results}

The temperature curves during heating the samples at various rates are represented in Fig. 1. For each of the three different heating rates a sudden drop is observed after the initial stage. For the lowest heating rate, the initial value of $800^{\circ} \mathrm{C} / \mathrm{s}$ drops to approximately $300^{\circ} \mathrm{C} / \mathrm{s}$ at $650^{\circ} \mathrm{C}$ whereas the intermediate rate of $2500^{\circ} \mathrm{C} / \mathrm{s}$ decreases to $1000^{\circ} \mathrm{C} / \mathrm{s}$ at $730^{\circ} \mathrm{C}$ and the highest heating rate of $4500^{\circ} \mathrm{C} / \mathrm{s}$ is suddenly reduced to $3000^{\circ} \mathrm{C} / \mathrm{s}$ at approximately $740^{\circ} \mathrm{C}$. It is assumed that this is due either to the latent heat dissipation of the re- covery or recrystallization process, or either to the drop in resistivity as a result of these thermally activated processes.

The heating curves also show a small deflection point at more elevated temperatures, which presumably can be attributed to the $\alpha-\gamma$ phase transformation. It can be observed that this second deflection point occurs at a temperature of 950 to $1050^{\circ} \mathrm{C}$ which can be compared to the $\mathrm{Ac}_{1}$ temperature of approximately $980^{\circ} \mathrm{C}$, during conventional heating rates of $\sim 10^{\circ} \mathrm{C} / \mathrm{s}$.

Figure 2 presents the microstructures of these samples, submitted to three different heating rates, in the three different conditions: (i) near to the end of recrystallization (i.e. with a recrystallized volume fraction of $>95 \%$ ), (ii) in the fully recrystallized condition with some degree of grain growth (before $\alpha-\gamma-\alpha$ transformation) and (iii) after the full $\alpha-\gamma-\alpha$ transformation. With a recrystallized volume fraction of $95 \%$ all microstructures display a nearly 
Table 1. Grain size data obtained for the different heating rates and in various stages of the microstructural evolution. $\bar{d}_{\mathrm{RX}}=$ average ferrite grain size with $95 \%$ volume fraction of recrystallized grains, $\bar{d}_{\text {before } \alpha-\gamma-\alpha}$ and $\bar{d}_{\text {after } \alpha-\gamma-\alpha}$, represent the ferrite grain size at the onset and after completion of the double phase transformation, respectively. The estimated Ac1 temperatures are also listed.

\begin{tabular}{|c|c|c|c|c|c|c|}
\hline $\begin{array}{c}\text { Heating } \\
\operatorname{rate}\left({ }^{\circ} \mathrm{C} / \mathrm{s}\right)\end{array}$ & $\begin{array}{c}\text { Temp. } \\
\text { Start RX } \\
\left({ }^{\circ} \mathrm{C}\right)\end{array}$ & $\begin{array}{c}\text { Temp. } \\
\text { End RX } \\
\left({ }^{\circ} \mathrm{C}\right)\end{array}$ & $\begin{array}{c}\overline{\mathrm{d}}_{\mathrm{RX}} \\
(95 \%) \\
(\mu \mathrm{m})\end{array}$ & $\begin{array}{c}\overline{\mathbf{d}_{\text {before } \alpha-\gamma-\alpha}} \\
\text { transformation } \\
(\mu \mathrm{m})\end{array}$ & $\begin{array}{c}\overline{\mathbf{d}}_{\text {after } \alpha-\gamma-\alpha} \\
\text { transformation } \\
\qquad(\mu \mathrm{m})\end{array}$ & $\begin{array}{l}\text { Ac1 } \\
\left({ }^{\circ} \mathrm{C}\right)\end{array}$ \\
\hline 800 & $\sim 700$ & $\sim 800$ & 4.2 & 14.4 & 17.0 & 950 \\
\hline 2500 & $\sim 690$ & $\sim 830$ & 3.6 & 6.0 & 26.0 & 990 \\
\hline 4500 & $\sim 770$ & $\sim 890$ & 2.0 & 6.0 & 16.0 & 1050 \\
\hline
\end{tabular}

equiaxed morphology of the recrystallized grains, cf. Figs. 2(a)-2(c). In the subsequent step the recrystallized grains do not only consume the last remains of the deformed matrix, but also a considerable degree of grain growth has occurred among the grains that had already recrystallized, cf. Figs. 2(d)-2(f). This is confirmed by quantitative grain size data, which are represented in Table 1. These grains size data are obtained by post-processing the orientation scans in which a $15 \mathrm{deg}$ misorientation was imposed as a tolerance threshold to separate one orientation from the other. Figs. 2(g)-2(i) display the microstructures after the material was reheated into the full austenite range and was submitted to the $\alpha-\gamma-\alpha$ transformation. In contradiction to expectations, this double transformation has produced considerably coarser structures as compared with the recrystallized structures. These observations are also confirmed by the grain size data of Table 1 .

The analysis of the orientation maps allowed establishing the correspondence between the features of the heating curves of Fig. 1 and the microstructural changes. For the three heating rates, the first deflection point of the heating curves marks the start of recrystallization. By analyzing partially recrystallized samples the start and finish temperature of recrystallization was determined (cf. Table 1). The data show that a significant effect on the recrystallization kinetics is only observed after the highest heating rate of $4500^{\circ} \mathrm{C} / \mathrm{s}$ (initially), which increases the temperature of recrystallization with approximately $100^{\circ} \mathrm{C}$ as compared with the intermediate and lowest heating rates. Although the Ac1 temperature could not be precisely determined, it was clear that for the three applied heating rates the recrystallization was fully completed before the start of the austenite transformation.

In Fig. 3 the textures derived from the OIM data are shown. For each of the 3 heating rates the same conditions are considered as the ones already observed for the microstructures. The textures exhibited towards the end of recrystallization (Figs. 3(a)-3(c)) display an RD-ND fibre character (RD-fibre: $\langle 110\rangle / / \mathrm{RD}$ and ND-fibre: $\langle 111\rangle / / \mathrm{ND}$ ). The orientation maps show that the RD orientations are primarily present among the last non-recrystallized grains, whereas the ND fibre is dominant in the recrystallized fraction. This is similar to the behaviour of conventionally processed IF steels which also show that the deformed ori- entations of the ND fibre are the first to disappear by nucleation and growth of recrystallized nuclei, because they display the highest stored energy of plastic deformation. ${ }^{13)}$ The RD fibre grains, on the other hand, are the last to recrystallize, because they display the lowest stored energy of plastic deformation.

The textures observed in the fully recrystallized state but before the onset of the austenite transformation (Figs. 3(d)-3(f)) are very similar to the conventional IF deep drawing textures. For the low and intermediate heating rates the ND fibre displays a strong maximum on the $\{111\}\langle 211\rangle$ fibre component which is also a typical feature of the annealing texture obtained after a rolling reduction of $95 \%$. After heating at $4500^{\circ} \mathrm{C} / \mathrm{s}$ the ND fibre displays a maximum at the $\{111\}\langle 110\rangle$ component.

The textures obtained after the $\alpha-\gamma-\alpha$ phase transformation (cf. Figs. 3(g)-3(i)) reveal a very strong memory effect with respect to the recrystallization textures at the onset of the transformation. In contrast to the expected randomizing effect of a double phase transformation these textures are even slightly stronger than the recrystallization textures. Particularly the dominant texture component has intensified as a result of the transformation (i.e. $\{111\}\langle 211\rangle$ for the lowest and intermediate heating rate and $\{111\}\langle 110\rangle$ for the highest one). The slightly different behaviour observed at the highest heating rate is not necessarily a significant phenomenon as substantially less grains have been included in the OIM scan of this sample (cf. Fig. 3(i)).

\section{Discussion}

\subsection{Static Recrystallization}

These data show that in an annealing treatment as short as $1 \mathrm{~s}$ all samples are fully recrystallized. For the specimens reheated at a rate of $300^{\circ} \mathrm{C} / \mathrm{s}\left(800^{\circ} \mathrm{C} / \mathrm{s}\right.$ initially) the recrystallization occurred in the heating stage between $\sim 700^{\circ} \mathrm{C}$ and $900^{\circ} \mathrm{C}$ which corresponds to a time interval of $667 \mathrm{~ms}$. During this interval the recrystallized nuclei grow from their initial embryonal size of approximately $1 \mu \mathrm{m}$ to the fully grown size of $14 \mu \mathrm{m}$, which corresponds to an average growth rate of $\sim 20 \mu \mathrm{m} / \mathrm{s}$.

In comparison, Fig. 4 shows the data of a $95 \%$ cold rolled IF steel which was annealed with an annealing rate of $35^{\circ} \mathrm{C} / \mathrm{s}$. This heating rate is only marginally higher than the 


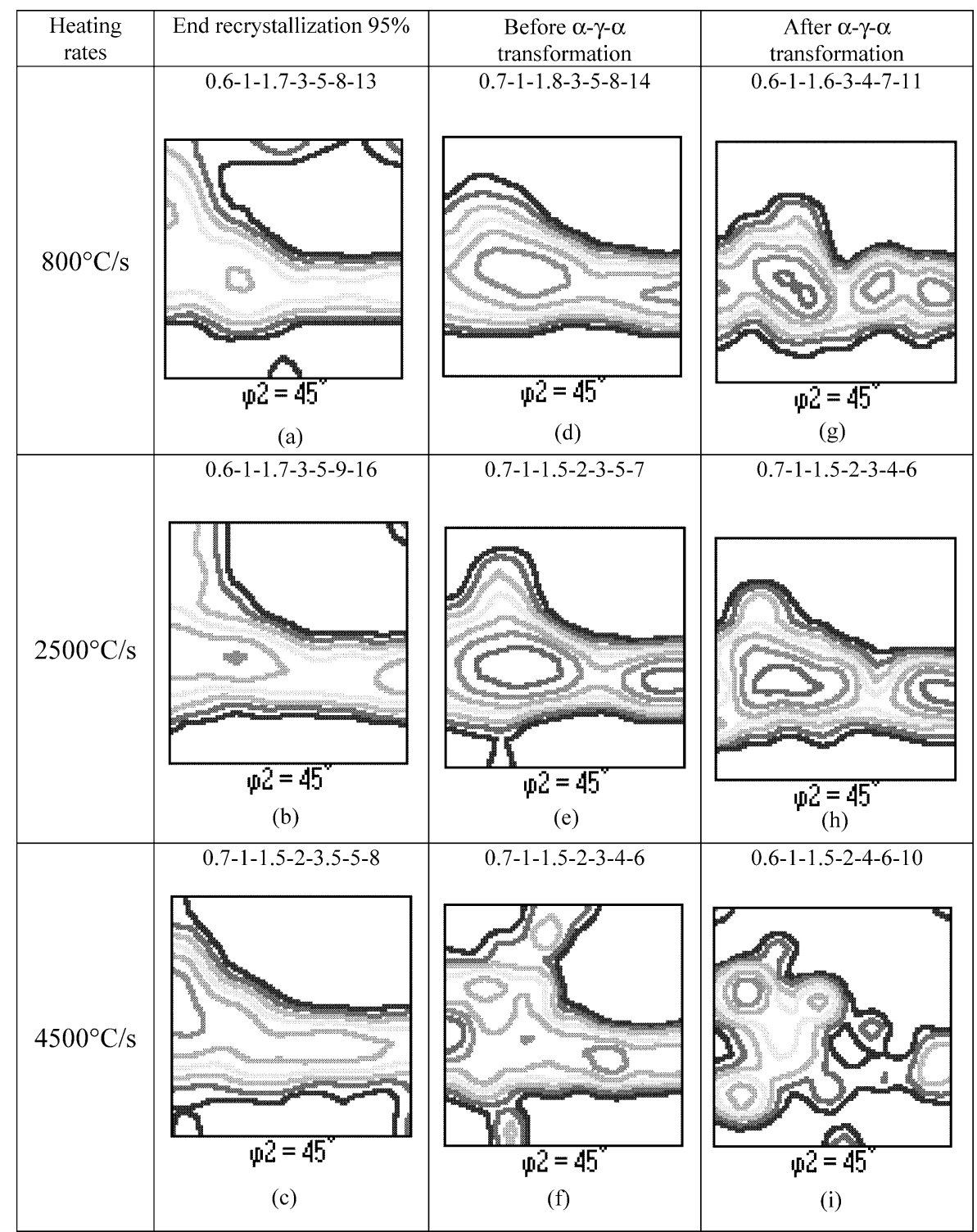

Fig. 3. Observed textures in TilF steel samples submitted to an ultra short annealing treatment with different heating rates. The iso-levels are mentioned at the top of each section.

heating rate of 5 to $10^{\circ} \mathrm{C} / \mathrm{s}$, which is applied in a conventional continuous annealing line of an industrial plant. It can be seen that this material, which started to recrystallize at $640^{\circ} \mathrm{C}$, has almost entirely recrystallized at $740^{\circ} \mathrm{C}$ and displays a fully recrystallized and grown structure at $900^{\circ} \mathrm{C}$. In this temperature range between $640^{\circ} \mathrm{C}$ and $900^{\circ} \mathrm{C}$, which represents an elapsed time of $7 \mathrm{~s}$, the recrystallized nuclei increased in average diameter from approximately 1 to 20 $\mu \mathrm{m}$. Thus, in an annealing treatment with a near conventional heating rate the average growth rate of the recrystallized grains was $2.7 \mu \mathrm{m} / \mathrm{s}$ which is one order of magnitude less than under rapid heating conditions.

Figure 5 shows how the average grain size of the fully recrystallized and grown structure decreases with increasing heating rate. All these data points are gathered for one specific IF steel which was submitted to a cold rolling reduction of $95 \%$. It is clear that the technique of rapid recrystallization does not produce a sub-microcrystalline microstructure, even though a substantial grain refinement is observed. The data seem to suggest that this grain refining effect has saturated beyond heating rates of $1000^{\circ} \mathrm{C} / \mathrm{s}$.
According to the well-known Hall-Petch relation, the decrease in grain size from 20 to $6 \mu \mathrm{m}$ which was observed here on increasing the heating rate from 35 to $1000^{\circ} \mathrm{C} / \mathrm{s}$ will give rise to an increase of the yield strength with a factor 1.83. When the typical yield strength of a conventional IF steel is $180 \mathrm{MPa}$, it means that by ultra-fast annealing this yield strength can be increased to approximately 320 $\mathrm{MPa}$ which is of the same magnitude as the yield strength of substitutionally strengthened IF steels (e.g. Mn-alloyed IF steels).

The grain size data obtained in this study are in reasonable agreement with data published by Muljono et al. ${ }^{14)}$ Although they did not exceed heating rates of $1000^{\circ} \mathrm{C} / \mathrm{s}$ a similar trend is observed of grain size decrease in both experiments. In the present study a somewhat lower grain size of $6 \mu \mathrm{m}$ is obtained at $1000^{\circ} \mathrm{C} / \mathrm{s}$ than the one of $12 \mu \mathrm{m}$, reported by Miljono et al. ${ }^{14)}$ This difference can be attributed to the higher rolling reduction $(95 \%$ vs. $70 \%)$ and the different steel composition (Ti stabilized $v s$. non-stabilized steel) which are considered here. Atkinson ${ }^{15)}$ reports an anomalous softening effect at ultra-high heating rates which 


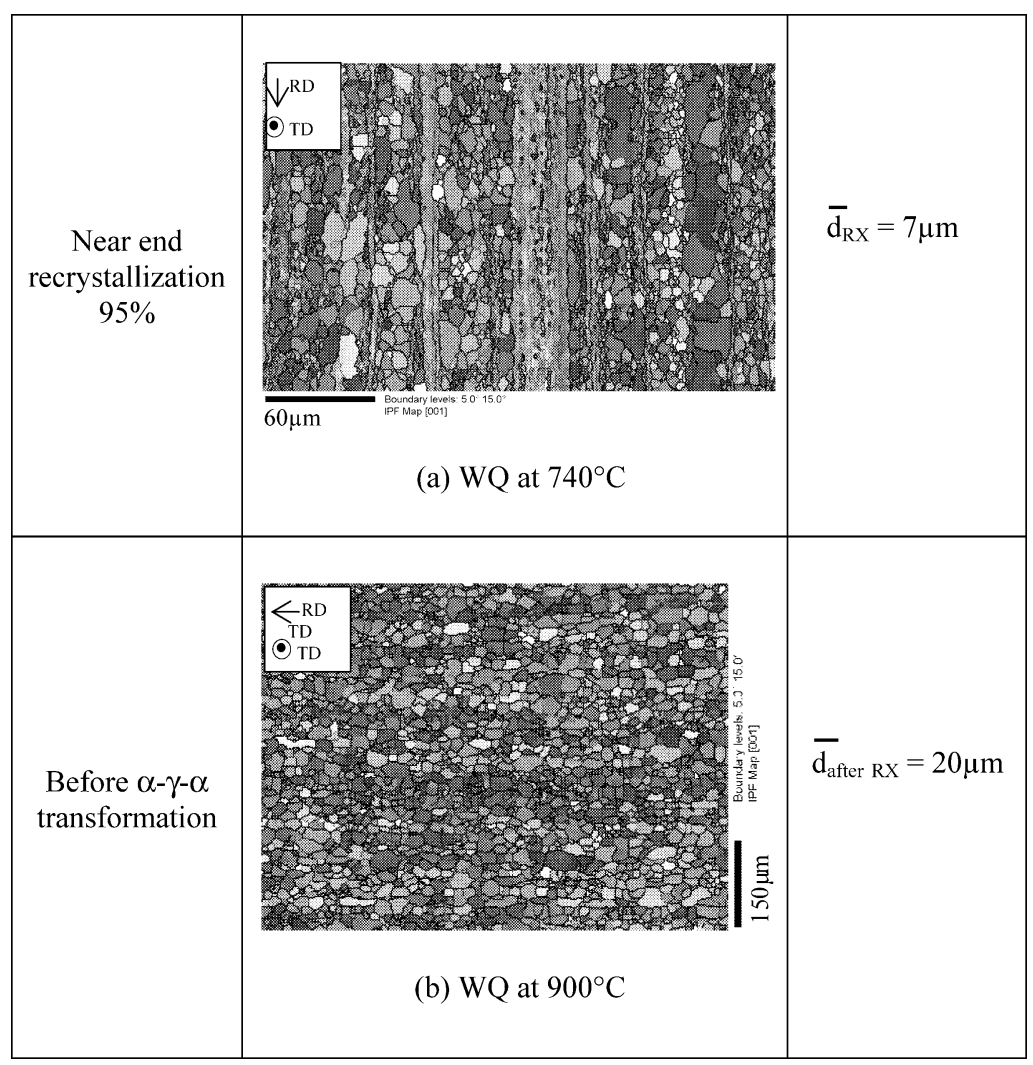

Fig. 4. IF steel $95 \%$ cold rolled and annealed with a heating rate of $35^{\circ} \mathrm{C} / \mathrm{s}$.

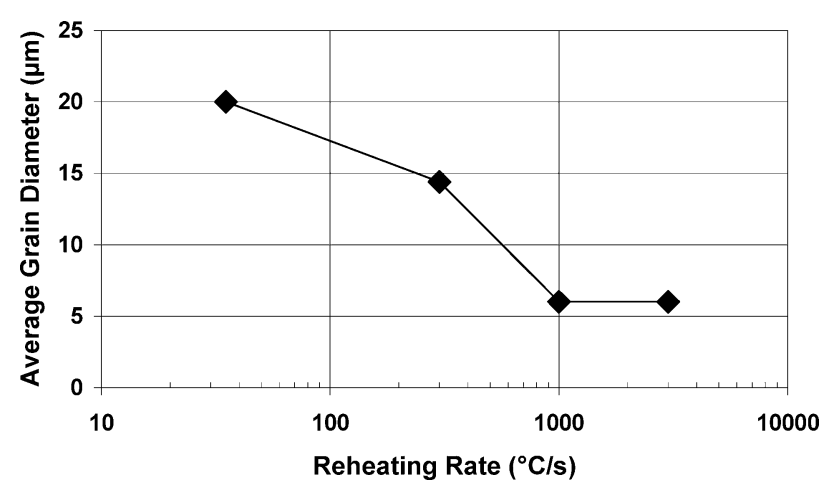

Fig. 5. Average grain size observed on the recrystallized structure of a $95 \%$ cold rolled TiIF steel, as a function of the heating rate. The data points refer to the samples mentioned in Table 1 and Fig. 4.

produces a reduction of the recrystallization temperature. Although a saturation of the grain refinement has been observed here at a heating rate of $>1000^{\circ} \mathrm{C} / \mathrm{s}$, it is not sure whether this phenomenon can be related to the type of anomalous softening reported by Atkinson. ${ }^{15)}$

The growth velocity, $v$, can be expressed as a product of two factors: the mobility $(m)$ and the driving force $(p)$ : $v=m \cdot p$. In a recrystallization event the driving force for growth originates from the energy of plastic deformation which is stored in the lattice matrix under the form of a dislocation density. This contribution, in a rough approximation, is temperature independent although the dislocation density at the onset of recrystallization is affected by the extent of static recovery prior to nucleation. The mobility factor, on the other hand, exhibits an exponential temperature dependence as it features the typical Arrhenius type behaviour of thermally activated phenomena.

In view of these considerations it can be understood that the nucleation rate will increase to some extent with increasing heating rate, as there is less time available for recovery and thus an increased dislocation density is present at the onset of nucleation. This mechanism will have a refining effect on the grain size. On the other hand, this grain refining tendency may be compensated by the increased average growth rate of the recrystallization nuclei as the growth stage of recrystallization was delayed to higher temperatures as a result of the rapid annealing cycle. This increased growth velocity will not only play a role in the dislocation driven stage, but also in the subsequent curvature driven normal growth stage. In the end, the final grain size will be the result of a compromise between these two opposing tendencies. Hence, the saturation of grain refinement can also be understood by taking into consideration the mobility factor. This may or may not play a concurrent role with the anomalous softening effect as reported by Atkinson. ${ }^{15)}$

The recrystallization textures which were observed after ultra-fast annealing are of the same type as the ones measured on conventionally annealed IF steels with a cold rolling reduction of $95 \%{ }^{11)}$ With heating rates of $800^{\circ} \mathrm{C} / \mathrm{s}$ and $2500^{\circ} \mathrm{C} / \mathrm{s}$ (initially) the fully recrystallized textures display a maximum on the $\{111\}\langle 211\rangle$ component (Figs. 3(d)-3(f)). As this maximum was virtually absent from the ODF just before the end of recrystallization, it can be concluded that it has primarily developed during the final stage of primary recrystallization and the subsequent grain growth stage. These observations are in full agreement with the analysis of Kestens and Jonas ${ }^{16)}$ which attributes the development of this component to preferred consumption of 
the $\{112\}\langle 110\rangle$ deformation component which is the dominant orientation among the last remains of the non-recrystallized matrix.

\section{2. $\alpha-\gamma-\alpha$ Transformation}

The present data show that opposed to common expectations, the forward and reverse $\alpha-\gamma$ transformations did not produce a grain refinement but has given rise to a grain coarsening which was also observed by Ushioda et al. ${ }^{17)}$ under conventional heating conditions on a Ti-Nb IF steel. In terms of texture development it can be observed that the double transformation features an important memory effect, unlike the samples of Ushioda et al. ${ }^{17)}$ which produced a near random texture after the $\alpha-\gamma-\alpha$ transformation. The ODF's of Figs. 3(g)-3(i) display even stronger ND fibres than the ones measured before the transformation. Texture memory under conventional heating circumstances was already observed by Yoshinaga ${ }^{18)}$ on a Mn alloyed IF steel. According to Gottstein et al. ${ }^{19)}$ the memory effect can be attributed to the fact that nucleation is restricted to triple junctions of the parent phase matrix.

According to the present authors another source of heterogeneous nucleation might have contributed to the coarsening effect. As the $\alpha-\gamma$ transformation starts in the carbon-rich sites of the parent phase microstructure, it is reasonable to assume that the regions in the vicinity of re-dissolving TiC particles will act as potential nucleation sites. According to Ryde et al. ${ }^{20)}$ also the texture memory effect might be attributed to this phenomenon, as they assume that the ferrite volume in the vicinity of these $\mathrm{TiC}$ particles never transforms to austenite during the entire annealing cycle. Hence, those residual ferrite grains will act as heterogeneous nucleation sites during the back transformation. A further justification of the role of heterogeneous nucleation is presented by the micrographs of Fig. 6 which feature the structures of a $75 \%$ cold rolled Extra Low Carbon (ELC) steel before and after the double $\alpha-\gamma$ transformation. One sample was immediately quenched after hot rolling and, as a consequence, it contained a large amount of $\mathrm{C}$ in supersaturated solid solution. Another sample was slowly cooled after hot rolling and thus, sufficient time was given to the carbon to precipitate as cementite.

It can be seen that the grain coarsening was absent after austenite annealing (Figs. 6(a) and 6(b)) for the samples that were quenched after hot rolling. For the slowly cooled samples the double transformation had produced a substantial grain coarsening (Figs. 6(c) and 6(d)). It can be readily assumed that in the water quenched ELC steel the $\mathrm{C}$ was more homogeneously distributed in the parent matrix which resulted in a more homogeneous austenite nucleation and thus a finer high temperature structure which eventually also produced a finer final structure.

In order to achieve the target of delaying the completion of recrystallization until the onset of $\alpha-\gamma-\alpha$ transformation it is necessary to add strong recrystallization retarding alloying elements. The microstructure of Fig. 7 displays a steel with a typical middle alloyed composition $(0.11 \% \mathrm{C}$, $1.26 \% \mathrm{Si}$ and $1.53 \% \mathrm{Mn}$ ), which was cold rolled to a re-

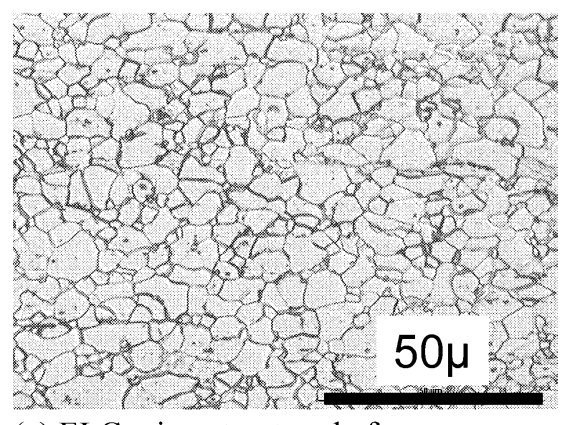

(a) ELC microstructure before $\alpha-\gamma-\alpha$ transformation (water quenched).

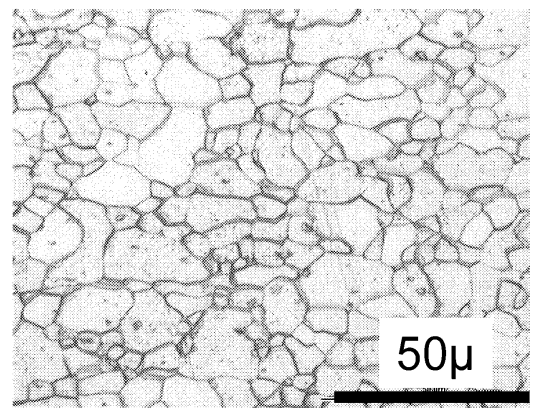

(c) ELC microstructure before $\alpha-\gamma-\alpha$ transformation (slowly cooled).

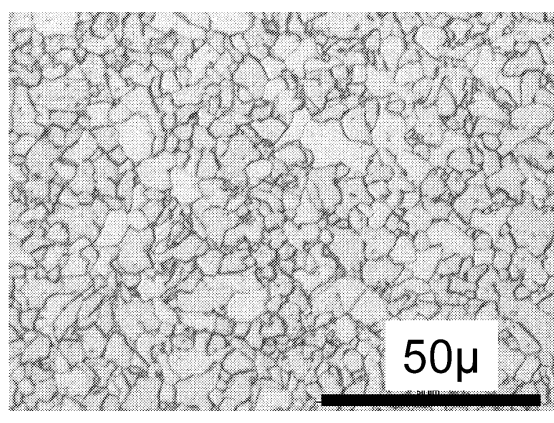

(b) ELC microstructure after $\alpha-\gamma-\alpha$ transformation (water quenched).

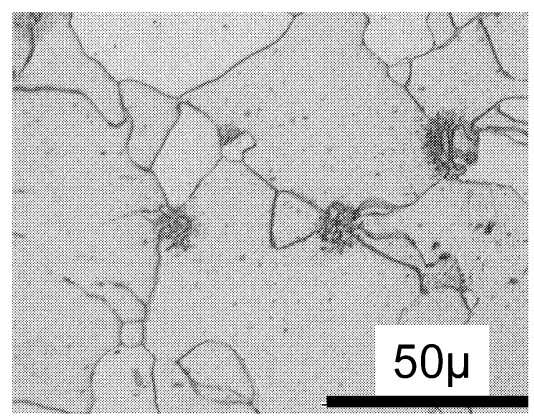

(d) ELC microstructure after $\alpha-\gamma-\alpha$ transformation (slowly cooled).

Fig. 6. Microstructures observed after ultra rapid annealing of $75 \%$ cold rolled ELC steel before and after $\alpha-\gamma-\alpha$ transformation. (a) and (b) pertain to a sheet which was water quenched after hot rolling with respective grain sizes of 3.9 and $4.7 \mu \mathrm{m}$. (c) and (d) apply to a sheet which was slowly cooled after hot rolling, respective grain sizes of 4.1 and $17.1 \mu \mathrm{m}$ respectively. 


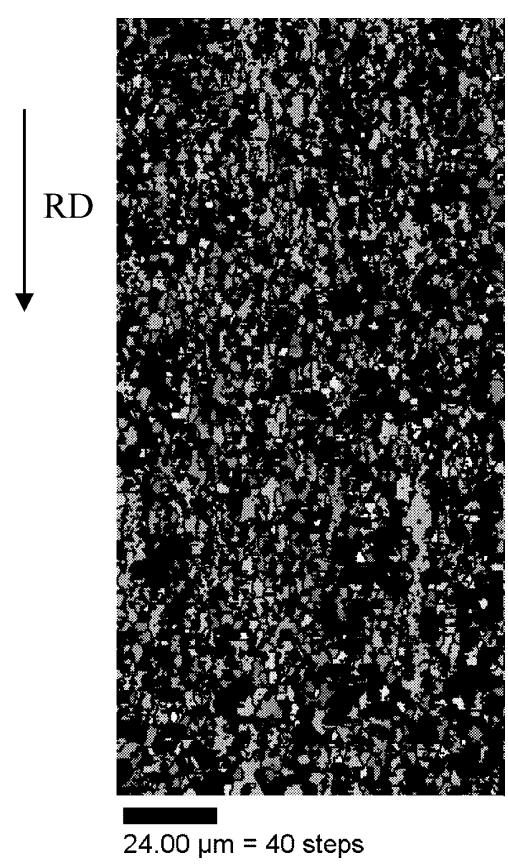

Fig. 7. OIM scan observed on $83 \%$ cold rolled $\mathrm{Si}-\mathrm{Mn}$ alloyed steel, after ultra fast annealing (with heating rate of $3000^{\circ} \mathrm{C} / \mathrm{s}$ ) to $840^{\circ} \mathrm{C} / \mathrm{s}$ and water quenching. The microstructure displays a mixture of deformed ferrite orientations (grey elongated colonies) and martensite grains (black) which emerged after the quench from the intercritical regions.

duction of $83 \%$, ultra fast annealed with a heating rate of $3000^{\circ} \mathrm{C} / \mathrm{s}$ and water quenched at $840^{\circ} \mathrm{C}$. In this microstructure both deformed ferrite and martensite are concurrently present, which indicates that the material had already entered the two-phase region before the end of recrystallization. In this particular example the formation of ultra-fine ferrite was prevented by the martensitic transformation, due to the increased $\mathrm{C}$-content.

\section{Conclusion}

Ultra-rapid heating rates of $300^{\circ} \mathrm{C} / \mathrm{s}$ to $4000^{\circ} \mathrm{C} / \mathrm{s}$ were applied with the intention to study the development of the microstructure and the texture on a Ti-added interstitial free steel. By ultra-short annealing of a cold rolled sheet with a reduction of $95 \%$, an average grain size could be obtained of $6 \mu \mathrm{m}$ in the fully recrystallized condition. This represents a considerable structural refinement with respect to the reference of $20 \mu \mathrm{m}$ which is normally observed in conventionally processed cold rolled IF steels.

Although the heating has given rise to an increase of the recrystallization temperature, the recrystallization was fully terminated before the onset of the ferrite to austenite phase transformation. It was observed that an ultra-short annealing treatment in the fully austenite phase produced a grain coarsening, very much similar as under conventional annealing conditions. This coarsening effect was attributed to a heterogeneous nucleation phenomenon.

An increase of the heating rate of 1000 to $4000^{\circ} \mathrm{C} / \mathrm{s}$ did not lead to finer structures than the limiting $6 \mu \mathrm{m}$ average grain size mentioned before. The saturation of grain refinement beyond heating rates of $1000^{\circ} \mathrm{C} / \mathrm{S}$ was discussed in terms of a compromise between driving force for nucleation and grain growth velocity.

The texture investigation revealed the formation of the characteristic $\{111\}$ fibre texture, irrespective of the heating rate, and in an annealing treatment as short as $0.3 \mathrm{~s}$. This $\{111\}$ fibre texture had even intensified after the $\alpha-\gamma-\alpha$ transformation, hence revealing a strong transformation texture memory.

\section{Acknowledgement}

The authors gratefully acknowledge the financial support for this work, granted by the Institute for the Promotion of Innovation by Science and Technology in Flanders (IWT).

\section{REFERENCES}

1) R. Z. Valiev: Mater. Sci. Eng. A 234-236 (1997), 59.

2) T. C. Lowe and R. Z. Valiev: JOM, (2000), 27.

3) T. Úngar, I. Alexandeov and M. Zehetbauer: JOM, (2000), 34

4) S. Takaki and Y. Kimura: J. Jpn. Soc. Powder Powder Metall., 46 (1999), No. 12, 1235.

5) T. G. Langdon, M. Nemoto and Z. Horita: JOM, (2000), April, 30.

6) S. V. Dobatkin, R. Z. Valiev, N. A. Krasilnikov and V. N. Konenkova: The 4th Int. Conf. on Recrystallization and Related Phenomena, The Japan Institute for Metals, Sendai, (1999), 913.

7) G. Winther, N. Hansen, T. Hebesberger, X. Huang, R. Pippan and M. Zehetbauer: Proc. of the 22nd Risø Int. Symp. on Materials Science: Science of Metastable and Nanocrystalline Alloys. Structure, Properties and Modelling, Risø National Laboratory, Roskilde, (2001), 435.

8) M. J. Zehetbauer: Proc. TMS Conf. Ultrafine Grained Materials II, TMS, Warrendale, PA, (2002), 669.

9) G. L. Kelly, H. Beladi and P. D. Hodgson: Proc. 1st Int. Conf. on Advanced Structural Steels, NIMS, Tsukuba, (2002), 13.

10) H. Dong. Proc. 1st Int. Conf. on Advanced Structural Steels, NIMS, Tsukuba, (2002), 15.

11) A. C. C. Reis, L. Kestens and Y. Houbaert: Proc. of the 22nd Risø Int. Symp. on Materials Science: Science of Metastable and Nanocrystalline Alloys. Structure, Properties and Modelling, Risø National Laboratory, Roskilde, (2001), 383.

12) P. van Houte: User Manual, MTM-FHM Software, Ver. 2ed. By MTM-KULeuven, (1995).

13) D. Vanderschueren, N. Yoshinaga, K. Koyama: ISIJ Int. 36 (1996), 1046.

14) D. Miljono, M. Ferry and D. P. Bunne: Mater. Sci. Eng. A, A303 (2001), 90 .

15) M. Atkinson: Mater. Sci. Eng. A, A262 (1999), 33.

16) L. Kestens and J. J. Jonas: Met. Mater., 5 (1999), 419.

17) K. Ushioda, N. Yoshinaga, K. Koyama and O. Akisue: Proc. Int. Forum for Physical Metallurgy of IF Steels, ISIJ, Tokyo, (1994), 227.

18) N. Yoshinaga: PhD Thesis, Dept. Metallurgy and Materials Science, Ghent University, Belgium, (1999).

19) G. Bruckner, J. Pospiech, I. Seidl and G. Gottstein: Scr. Mater., 44 (2001), 2635.

20) L. Ryde, D. Artymowicz and W. B. Hutchinson: Proc. of the 12th Int. Conf. on Textures of Materials, Vol. 2, National Research Council of Canada, Research Press, Ontario, (1999), 1031. 